\title{
Effect of phenobarbital on inducing insecticide tolerance and esterase changes in Aedes aegypti (Diptera: Culicidae)
}

\author{
Rita de Cássia Sousa-Polezzi and Hermione Elly Melara de Campos Bicudo \\ Universidade Estadual Paulista, Instituto de Biociências, Letras e Ciências Exatas, São José do Rio Preto, \\ SP, Brasil.
}

\begin{abstract}
The effect of phenobarbital (PB) on the induction of tolerance to the organophosphorous insecticide temephos (TE) was investigated in Aedes aegypti L4 larvae submitted to two different PB-treatments:(1) continuous treatment from the egg to the larval L4 stage and (2) discontinuous treatment in which L4 larvae were exposed for $30 \mathrm{~h}$. Mosquitoes from two Brazilian cities were studied: São José do Rio Preto (SJ) in São Paulo State and Goiânia (GO) in Goiás State. According to criterions established by World Health Organization (WHO) mosquitoes from SJ are organophosphate-susceptible while mosquitoes from GO are organophosphate-resistant. For both SJ and GO larvae the two different PB-treatments resulted in significantly increased tolerance (measured by reduced mortality) to $0.01 \mathrm{mg} / \mathrm{L}$ TE while for larvae exposed to $0.02 \mathrm{mg} / \mathrm{L}$ TE only continuous PB-treatment resulted in significantly increased TE-tolerance. The reduction of mortality rate was greater in SJ larvae than in GO larvae, confirming data from other organisms indicating that the effect of $\mathrm{PB}$ is more pronounced in susceptible strains. To test if oxidase enzymes were involved in PB-induced tolerance we treated PB-pretreated SJ and GO larvae with the oxidase inhibitor piperonyl butoxide (PBO) before exposure to TE and observed increased (rather than decreased) tolerance, suggesting that oxidases are not involved in the tolerance process and that PB and PBO can act in concert or synergistically. Esterase patterns of PB-pretreated larvae indicated that the cholinesterases EST-13 and EST-14 are involved in the PB-induced TE- tolerance, reinforcing a previous study carried out in our laboratory which suggested that increased esterase synthesis is the mechanism responsible for the development of insecticide resistance in Aedes aegypti.
\end{abstract}

Key words: Aedes aegypti, insecticide resistance, phenobarbital, tolerance, pyperonyl butoxide, esterases.

Received: April 30, 2003; Accepted: November 14, 2003.

\section{Introduction}

In mammals and insects, organophosphorous insecticides are detoxified by several enzymes such as cholinesterases, carboxylesterases, oxidases and glutathione-Stransferases (GSTs), which act by reducing the amount of free organophosphate (OP) molecules (Terriere, 1984; Kaliste-Korhonen et al., 1998). The detoxification system may be enhanced by chemical stimuli, leading to the production of additional enzymes and causing insecticide tolerance (Scott, 1995). A wide variety of chemicals have been shown to elicit this inductive response. Among them is the barbiturate phenobarbital (PB) which has been used in research into OP insecticide toxicity in organisms such as flies (Scott and Lee, 1993; Fuchs et al., 1994) and rodents (Clement, 1983; Kaliste-Korhonen et al., 1990). Data in the literature has shown that PB moderately decreases

Send correspondence to H.E.M.C. Bicudo. Universidade Estadual Paulista, Instituto de Biociências, Letras e Ciências Exatas, (IBILCE/ UNESP), Rua Cristóvão Colombo 2265, 15054-000 São José do Rio Preto, SP, Brasil. E-mail: bicudo@bio.ibilce.unesp.br. the toxic response to some OPs and increases the insecticide $\mathrm{LD}_{50}$ values. For the OP soman, this increase was two to twelvefold in rats and two to threefold in mice (Dubois and Knoshita, 1968; Clement, 1983).

Tolerance caused by treatment with PB has been mainly attributed to the induction of carboxylesterases, cholinesterases and cytochrome P-450 isozymes (Ali et al., 1985; Carino et al., 1994; Fuchs et al., 1994; KalisteKorhonen et al. 1998). In rat liver, PB increased the activity of three distinct carboxylesterases by three to eightfold (Ali et al., 1985), while in Drosophila melanogaster PB-treated, the activity of cytochrome P450 enzymes increased by up to 2.5 times, being the induction dose-dependent (Fuchs et al., 1994).

The mechanism or mechanisms by which PB increases enzyme activity in eukaryotes remains unknown, although the hypothesis that insecticide resistance and PB induction involve the same genetic mechanisms is frequently mentioned in the literature (Plapp, 1984; Terriere 1984; Scott and Lee, 1993; Liu and Scott, 1997). 
In recent years our research group has been involved in the study of the development of resistance to insecticides and the mechanisms of such resistance in some Brazilian populations of the mosquito Aedes aegypti, which is currently one of the most widespread disease vectors in the world. Dengue, dengue hemorrhagic fever and yellow fever are diseases caused by viruses maintained in a cycle that involves humans and A. aegypti. The results of one of our previous studies in $A$. aegypti from the city of São José do Rio Preto in the State of São Paulo suggested that changes detected in the esterase synthesis could be related to the 20 -year struggle by sanitary authorities to control these mosquitoes with intensive use of insecticides (Lima-Catelani et al., 2004).

In the research reported in the current paper, we describe the effect of PB-treatment on the induction of tolerance to the organophosphorous insecticide temephos (TE), in two Brazilian populations of $A$. aegypti of different OP-susceptibility. One of these populations is from the city of Goiânia in the State of Goiás (GO) and the other is the already mentioned population from São José do Rio Preto in the State of São Paulo (SJ). According to the criterions established by the World Health Organization (WHO) GO is OP-resistant (Macoris et al., 1995) while SJ, although showing a small decrease of insecticide-susceptibility is still considered OP-susceptible (Macoris et al., 1999).

\section{Materials and Methods}

\section{Mosquitoes}

Four stages characterize the development of $A$. aegypti, which is a holometabolous insect: egg, larva (with subphases L1, L2, L3, L4), pupa and adult.

Larvae and pupae of $A$. aegypti were collected in São José do Rio Preto (SJ) by people who work in the Superintendency for the Control of Endemic Diseases (Superintendência de Controle de Endemias do Estado de São Paulo: SUCEN) from tires, cans, bottles and other $A$. aegypti usual breeding sites and brought to be raised in the Laboratory of Vectors at IBILCE-UNESP. Eggs of the mosquitoes from Goiânia (GO) were supplied by Dr. Ionizete Garcia da Silva from the Institute of Tropical Pathology and Public Health, Federal University of Goiás, Goiânia (Instituto de Patologia Tropical e Saúde Pública, Universidade Federal de Goiás, Goiânia) and also raised in the Laboratory of Vectors. The present work was carried out in 2000 and 2001.

\section{Phenobarbital treatment}

Mosquitoes were exposed to phenobarbital (PB) (Gardenal ${ }^{\circledR}$, Rhodia Farma, Brazil) using two different treatments: (1) continuous treatment, in which $A$. aegypti eggs were allowed to develop in a $0.2 \mathrm{mg} / \mathrm{mL}$ PB aqueous solution until L4 larval stage was reached (which took about one week) and (2) discontinuous treatment, in which
L4 larvae were treated during $30 \mathrm{~h}$ in $0.26 \mathrm{mg} / \mathrm{mL}$ PB aqueous solution. Eggs and larvae were kept in Petri dishes containing $40 \mathrm{~mL}$ of the solution, under suitable physical conditions for normal development. Simultaneously to the treatments, controls were made using water without the addition of $\mathrm{PB}$.

\section{Exposure to the organophosphate temephos}

PB-pretreated and control (untreated with PB) L4 larvae from $\mathrm{SJ}$ and $\mathrm{GO}$ were exposed to three concentrations $(0.005,0.01$ and $0.02 \mathrm{mg} / \mathrm{L})$ of the organophosphorous insecticide temephos (TE) (Abate $\AA$, Cyanamid, Brazil) in aqueous solutions. In each test, groups of 10 larvae were exposed to every insecticide concentration in Petri dishes containing $40 \mathrm{~mL}$ of the solution. Two other types of parallel controls were made, some groups of 10 larvae being placed in PB solution in the same concentration as that to which PB-pretreated larvae had been exposed, while other groups were placed in water only. Larval mortality was evaluated after $24 \mathrm{~h}$.

\section{Piperonyl butoxide treatment}

The action of the oxidase inhibitor piperonyl butoxide (PBO) (Acros Organics, U.S.A.) was investigated by subjecting different groups of 10 larvae to different combinations of treatments as follows: (a) PB-untreated L4 larvae were placed into $6.0 \mu \mathrm{L} / \mathrm{L}$ PBO aqueous solution for $24 \mathrm{~h}$ and then into $0.01 \mathrm{mg} / \mathrm{L}$ TE aqueous solution for a further $24 \mathrm{~h}$; (b) PB-discontinuously-pretreated L4 larvae were placed into a $6.0 \mu \mathrm{L} / \mathrm{L}$ PBO plus $0.01 \mathrm{mg} / \mathrm{L}$ TE aqueous solution for $24 \mathrm{~h}$; (c) PB-discontinuously-pretreated larvae were placed into a $10 \mu \mathrm{L} / \mathrm{L}$ PBO aqueous solution for $4 \mathrm{~h}$ and then exposed to $0.01 \mathrm{mg} / \mathrm{L} \mathrm{TE}$ aqueous solution for $24 \mathrm{~h}$. In every case, controls were performed omitting the $\mathrm{PBO}$ in the sequence of treatments.

\section{Esterase patterns}

The esterase patterns of L4 larvae, pupae and male and female adult $A$. aegypti taken from continuous and discontinuous PB treatments along with untreated controls were examined. Esterase analysis was carried out using $(8 \%)$ polyacrylamide gel electrophoresis (PAGE) (Laemmli, 1970). The mosquitoes were individually squashed in $25 \mu \mathrm{L}$ of buffer (1.5 M Tris-HCl, $\mathrm{pH} 8.8$, plus $10 \%$ glycerol) and the mixture allowed to stand until the supernatant separated, $10 \mu \mathrm{L}$ of the supernatant being used in each sample dropped onto the gel. Electrophoresis was performed for two hours at $\sim 25^{\circ} \mathrm{C}$ using a constant voltage of $200 \mathrm{~V}$ and $0.1 \mathrm{M}$ Tris-glycine $(\mathrm{pH} 8.3)$ solution as the running buffer. After electrophoresis, esterases were identified in the gels as described by Johnson et al. (1966) and Steiner and Johnson (1973), by pre-incubating the gels for $45 \mathrm{~min}$ at $25^{\circ} \mathrm{C}$ in $50 \mathrm{~mL} 0.1 \mathrm{M}$ aqueous sodium phosphate $(\mathrm{pH}$ 6.2) followed by staining the gels in the dark for one hour with a solution containing $30 \mathrm{mg}$ of -naphthyl acetate and 
$15 \mathrm{mg}$ of $\beta$-naphthyl acetate as substrates, $60 \mathrm{mg}$ of fast blue and $5 \mathrm{~mL}$ of $\mathrm{N}$-propanol in $50 \mathrm{~mL}$ of $0.1 \mathrm{M}$ aqueous sodium phosphate solution. The gels were dried at room temperature using gelatin and cellophane wound slab gels in an embroidering hoop (Ceron et al., 1992). The esterase bands in the gels were numbered according to the system of Lima-Catelani et al., 2004.

\section{Esterase Activity}

The activity of esterases in polyacrylamide gels of pupae submitted to continuous treatment with PB was evaluated by using the Global Lab Image Program (SP0550, Data Translation, Inc., MA, USA), a Windows ${ }^{\circledR}$-based monochrome image processing and analysis package. In this method the intensity analysis is displayed in linear profiles and histograms. The profile tool graphs the gray values (in the present study equating to the intensity of band staining) along a line segment in an image (in this study being the horizontal sequence of bands in the gel). The horizontal axis of the resultant profile graph represents the points along the line segment while the vertical axis represents the pixel value at each point. The full range of grayscale values is from 0 (completely black) to 255 (the absence of color), between which lie intermediate shades of gray. In the present study, the grayscale values given to the bands by the program were used for comparison between treatments and controls.

\section{Statistics}

Treatments were compared using the chi-squared $\left(\chi^{2}\right)$ test for homogeneity (Mood et al., 1974).

\section{Results}

\section{Susceptibility to TE of PB-pretreated and non-pretreated L4 larvae}

As shown in Table 1, no mortality of L4 larvae occurred in either water (control) or PB aqueous solution, while in TE aqueous solution mortality of both SJ and GO larvae increased with increasing TE concentration. In the tests involving discontinuous and continuous PB pretreatment the percentage mortality also increased with increasing TE concentration.

In comparisons between PB-pretreated and non-pretreated SJ and GO larvae the mortality of larvae exposed to TE decreased in every test involving pretreated larvae, although the decrease in mortality was only significant for every comparison when TE concentration was $0.01 \mathrm{mg} / \mathrm{L}$ (Table 1). In the discontinuous pretreatment, decreased mortality of the SJ larvae was also significant at $0.005 \mathrm{mg} / \mathrm{L} \mathrm{TE}$, while in the continuous pretreatment decreased mortality was significant for both the SJ and OP populations at $0.02 \mathrm{mg} / \mathrm{L} \mathrm{TE}$.

Comparisons between the SJ and GO populations regarding percentage mortality of L4 larvae in tests without

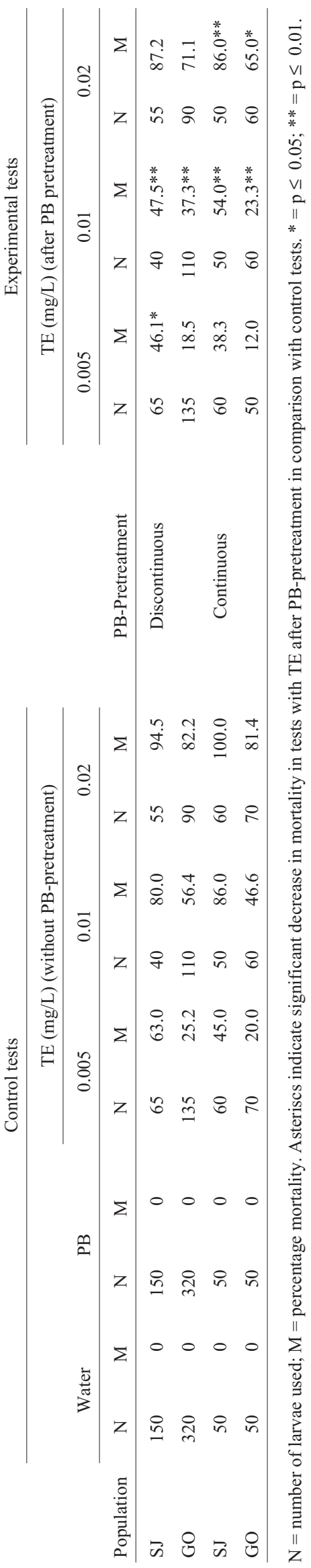


pretreatment or with discontinuous or continuous PB pretreatment, followed by exposure to TE showed significantly higher mortality values for SJ larvae for both types of pretreatment in every comparison except for discontinuous $\mathrm{PB}$ pretreatment in which larvae were exposed to $0.01 \mathrm{mg} / \mathrm{L}$ TE (Table 2). This data was computed from Table 1, calculating the mortality difference between SJ and GO populations in PB-pretreated and non-pretreated mosquitoes.

\section{Effect of piperonyl butoxide (PBO) on mortality of L4 larvae exposed to TE}

As shown in Table 3, a reduction in mortality occurred in experiments in which PB-pretreated larvae were exposed to $\mathrm{PBO}$ and $0.01 \mathrm{mg} / \mathrm{mL}$ TE simultaneously or in which exposure to TE occurred after PBO treatment. In both cases mortality was significantly lower than in the experiments in which larvae were not exposed to PBO. No mortality was observed in larvae exposed to PBO alone, in the concentrations used for 4- or 24-h treatments, before submitting them to TE.

In the experiments in which the mosquitoes were not PB-pretreated, the mortality differences between the experiments in which larvae were exposed to TE only and those in which the mosquitoes had been pretreated with PBO and then exposed to TE were not significant.

Esterase patterns of PB-pretreated mosquitoes from SJ population: changes in esterase frequency and activity

Esterase band patterns in polyacrylamide gels of mosquitoes from SJ population, in different developmental stages (L4 larvae, pupae and adult males and females), submitted to continuous or discontinuous PB treatments were compared to control mosquitoes (which had not been treated with PB) (Table 4). Significant expression variation, indicated by changes in the frequency of mosquitoes giving band in gels, was observed for PB-treated larvae in respect to bands EST-2 and EST-20 ( $\mathrm{p}<0.05$ ), which showed decreased frequency in the discontinuous treatment. In the continuous treatment, the frequencies of the same two bands and also band EST-4 were significantly reduced in larvae $(\mathrm{p}<0.01)$, but the frequency of the band
Table 3 - Comparative mortality (\%) of A. aegypti L4 larvae from São José do Rio Preto in tests using temephos (TE) only or piperonyl butoxide (PBO) or phenobarbital $(\mathrm{PB})$ before exposure to temephos $(\mathrm{PBO} \rightarrow \mathrm{TE}$ or $\mathrm{PB} \rightarrow \mathrm{TE})$, or using the sequence of treatments $(\mathrm{PB} \rightarrow \mathrm{PBO} \rightarrow \mathrm{TE}$ or $\mathrm{PB} \rightarrow \mathrm{PBO}+\mathrm{TE})$.

\begin{tabular}{lccc}
\hline PB-pretreatment & Test & $\mathrm{N}$ & $\mathrm{M}(\%)$ \\
\hline not PB pretreated & $\mathrm{TE}$ & 14 & 50.0 \\
& $\mathrm{PBO} \rightarrow \mathrm{TE}$ & 14 & 57.5 \\
PB pretreated & $\mathrm{PB} \rightarrow \mathrm{TE}$ & 30 & $40.0^{* *}$ \\
& $\mathrm{~PB} \rightarrow \mathrm{PBO}+\mathrm{TE}$ & 30 & 6.7 \\
PB pretreated & $\mathrm{PB} \rightarrow \mathrm{TE}$ & 40 & $52.5^{*}$ \\
& $\mathrm{~PB} \rightarrow \mathrm{PBO} \rightarrow \mathrm{TE}$ & 50 & 32.0 \\
\hline
\end{tabular}

$\mathrm{N}=$ number of larvae used; $\mathrm{M}=$ mortality percentage. Asteriscs indicate a significant difference in mortality in the comparison of the two tests for each PB-pretreatment $(*=\mathrm{p} \leq 0.05 ; * *=\mathrm{p} \leq 0.01)$.

EST-14 was significantly increased in larvae $(\mathrm{p}<0.01)$ and in pupae $(\mathrm{p}<0.05)$.

Changes in esterase activity evaluated on the basis of the degree of staining and thickness of the bands in the gels were observed for the continuous PB treatment. In the discontinuous tests the changes were not as evident as in the continuous ones. Bands EST-1, EST-13 and EST-14 showed the greatest changes in esterase activity. Band EST-1 showed decreased activity in larvae, pupae and adults but bands EST-13 and EST-14 showed an increased activity in the larval and pupal stages. Means of pixel numbers and standard deviations obtained for the three bands from treated and control pupae are set out in Table 5. Pupae were chosen for measurements because they showed the greatest activity increase in bands EST-13 and EST-14. Differences in pixel numbers between treated pupae and controls were significant for esterases EST-1 and EST-13. A polyacrylamide gel showing the esterase patterns, and the profile graphs of the three esterase bands are given in Figures 1 and 2, respectively.

\section{Discussion}

Insect resistance to insecticides is one of the central subjects as far as disease vectors or agricultural pests are

Table 2 - Comparison between the percentage mortality of São José do Rio Preto (SJ) and Goiânia (GO) A. aegypti exposed to the organophosphate temephos (TE) in tests with L4 larvae which had not been pretreated with phenobarbital (PB) and L4 larvae submitted to discontinuous and continuous pretreatments with PB.

\begin{tabular}{lccccc}
\hline & & & \multicolumn{2}{c}{ Mortality differences (\%) in temephos $(\mathrm{mg} / \mathrm{L})$ tests } \\
\cline { 4 - 6 } Comparisons & PB-pretreatment & Test & 0.005 & 0.01 & 0.02 \\
\hline \multirow{2}{*}{ SJ x GO } & Not pretreated & TE & $37.8^{* *}$ & $23.6^{* *}$ & $12.3^{*}$ \\
& Discontinuous & PB $\rightarrow$ TE & $27.6^{* *}$ & 10.2 & $16.1^{*}$ \\
& Not pretreated & TE & $25.0^{* *}$ & $39.4^{* *}$ & $18.6^{* *}$ \\
& Continuous & PB $\rightarrow$ TE & $26.3^{* *}$ & $30.7^{* *}$ & $21.0^{*}$ \\
\hline
\end{tabular}

Asteriscs indicate significant differences. $*=p \leq 0.05 ; *=p \leq 0.01$. 
Table 4 - Effect of PB-treatment on esterase patterns. Percentage of $A$. aegypti mosquitoes from São José do Rio Preto submitted to continuous and discontinuous treatments (T) with phenobarbital (PB) and controls (C) bearing the esterase bands during different developmental stages.

\begin{tabular}{|c|c|c|c|c|c|c|c|c|c|c|c|c|c|c|c|c|}
\hline \multirow[b]{3}{*}{$\mathrm{N}$} & \multicolumn{4}{|c|}{$\mathrm{C}$ (not PB-treated) } & \multicolumn{4}{|c|}{ (T) Discontinuous } & \multicolumn{4}{|c|}{ C (not PB-treated) } & \multicolumn{4}{|c|}{ (T) Continuous } \\
\hline & L4 & $\mathrm{P}$ & $\mathrm{F}$ & M & L4 & $\mathrm{P}$ & $\mathrm{F}$ & M & L4 & $\mathrm{P}$ & $\mathrm{F}$ & M & L4 & $\mathrm{P}$ & $\mathrm{F}$ & $\mathrm{M}$ \\
\hline & 60 & 50 & 28 & 32 & 60 & 50 & 28 & 32 & 63 & 67 & 39 & 39 & 73 & 67 & 41 & 41 \\
\hline \multicolumn{17}{|l|}{ Bands } \\
\hline EST-21 & 3.3 & - & - & - & 1.7 & - & - & - & - & - & - & - & - & - & - & - \\
\hline EST-20 & 80.0 & - & - & - & $58.3 *$ & - & - & - & 82.5 & - & - & - & $58.9^{* *}$ & - & - & - \\
\hline EST-19 & - & - & - & - & - & - & - & - & 11.1 & - & - & - & 4.1 & - & - & - \\
\hline EST-18 & - & - & - & - & - & - & - & - & 7.9 & - & - & - & - & - & - & - \\
\hline EST-16 & 1.7 & - & - & - & - & - & - & - & - & - & - & - & 9.5 & - & - & - \\
\hline EST-14 & 33.3 & 48.0 & 46.4 & 31.2 & 40.0 & 36.0 & 32.1 & 28.1 & 36.5 & 59.7 & 35.9 & 35.9 & $61.6^{* *}$ & $76.1^{*}$ & 46.3 & 26.8 \\
\hline EST-13 & 41.7 & 36.0 & 7.1 & 6.2 & 43.3 & 48.0 & 14.3 & 3.1 & 39.7 & 37.3 & 35.9 & 38.5 & 34.2 & 26.9 & 43.9 & 34.1 \\
\hline EST-12 & 20.0 & 8.0 & - & - & 18.3 & 18.0 & - & - & 9.5 & 10.4 & 12.8 & 17.9 & 13.7 & 6.0 & 14.6 & 17.1 \\
\hline EST-8 & 20.0 & - & - & - & 8.3 & - & - & - & 7.9 & - & - & - & - & - & - & - \\
\hline EST-7 & 55.0 & 50.0 & - & - & 55.0 & 44.0 & - & - & 22.2 & 53.7 & - & 53.8 & 30.1 & 55.2 & - & 53.6 \\
\hline EST-6 & 55.0 & 18.0 & 7.1 & - & 56.7 & 16.0 & 3.6 & - & 50.8 & 22.4 & - & 2.6 & 49.3 & 19.4 & - & 2.4 \\
\hline EST-5 & 31.7 & - & - & - & 20.0 & - & - & - & 15.9 & 7.5 & - & - & 20.5 & 3.0 & - & - \\
\hline EST-4 & 73.3 & 20.0 & - & - & 71.7 & 20.0 & - & - & 87.3 & 3.0 & 10.3 & - & $65.7^{* *}$ & 3.0 & 4.9 & - \\
\hline EST-3 & 30.0 & - & - & - & 38.3 & 2.0 & - & - & 41.3 & 1.5 & - & - & 28.8 & 3.0 & 4.9 & 9.8 \\
\hline EST-2 & 38.3 & - & - & - & $21.7^{*}$ & - & - & - & 46.0 & - & - & - & $23.3^{* *}$ & - & - & - \\
\hline EST-1 & 100 & 100 & 100 & 100 & 100 & 100 & 100 & 100 & 100 & 100 & 100 & 100 & 100 & 100 & 100 & 100 \\
\hline EST-A & - & - & - & - & 1.7 & 2.0 & - & - & - & 4.5 & - & - & - & - & - & - \\
\hline EST-B & 10.0 & - & - & - & 11.7 & - & - & - & 20.6 & 3.0 & - & - & 17.8 & 3.0 & - & - \\
\hline EST-C & 13.3 & - & - & - & 10.0 & - & - & - & 17.5 & 1.5 & - & - & 8.2 & 4.5 & - & - \\
\hline EST-D & 10.0 & 2.0 & - & - & 10.0 & 4.0 & - & - & 6.3 & 6.0 & - & - & 1.4 & 3.0 & - & - \\
\hline
\end{tabular}

$\mathrm{L} 4=$ fourth instar larvae; $\mathrm{P}=$ pupae; $\mathrm{F}=$ adult females; $\mathrm{M}=$ adult males; $\mathrm{N}=$ number of mosquitoes analyzed; - = absence of the bands. Asteriscs indicate significant differences between percentages in $\mathrm{C}$ and $\mathrm{T}$, in both discontinuous and continuous treatments $(*=\mathrm{p} \leq 0.05 ; * *=\mathrm{p} \leq 0.01)$.

concerned because resistance affects or may even hamper control programs. In recent years, the barbiturate phenobarbital (PB), which promotes increase in the insecticide tolerance, has been considered an important tool in the study of

Table 5 - Effect of PB-treatment on esterase band activity. Mean values and standard deviation in pixels obtained by Image Analysis of the esterase bands EST-1, EST-13 and EST-14, in gels prepared with control (C) and PB-pretreated (T) mosquitoes from São José do Rio Preto.

\begin{tabular}{lccc}
\hline Bands & Test & $\mathrm{N}$ & Pixel numbers $\bar{X} \pm S_{X}^{\leftarrow}$ \\
\hline EST-1 & $\mathrm{T}$ & 67 & $76.7 \pm 3.9^{*}$ \\
& $\mathrm{C}$ & 67 & $56.2 \pm 4.3$ \\
EST-13 & $\mathrm{T}$ & 18 & $174.2 \pm 9.7^{*}$ \\
& $\mathrm{C}$ & 26 & $194.1 \pm 4.2$ \\
EST-14 & $\mathrm{T}$ & 51 & $159.1 \pm 5.8$ \\
& $\mathrm{C}$ & 40 & $165.3 \pm 6.0$ \\
\hline
\end{tabular}

$\mathrm{N}=$ number of mosquitoes whose bands were measured. Significant differences in the comparison of pretreated and control band values $(*=\mathrm{p} \leq 0.05)$ resistance. The work described in this paper was carried out to provide information on the insecticide resistance mechanisms of $A$. aegypti, PB being used in tests with two Brazilian strains. One of them considered organophosphatesusceptible was collected from São José do Rio Preto (SJ) and the other, considered organophosphate-resistant was collected from Goiânia (GO) (Macoris et al., 1995; 1999).

Data on mortality obtained in the comparisons of PB-pretreated and non-pretreated larvae exposed to the insecticide TE (the organophosphate normally used by Brazilian sanitary authorities in larval control) showed that $\mathrm{PB}$ also causes insecticide tolerance in $A$. aegypti. In the light of the numbers, mortality of PB-treated larvae decreased in every comparison (Table 1). Considering only the significant data, this tolerance was more efficient at $0.01 \mathrm{mg} / \mathrm{L}$ of $\mathrm{TE}$, in which $\mathrm{PB}$ treatments differed from control in every test, in both populations. At this TE concentration, both PB-treatments (discontinuous, for $30 \mathrm{~h}$ or continuous from egg to larval stage (about one week) were efficient in providing protection against the insecticide. The PB-discontinuous treatment was also significantly efficient for SJ larvae at $0.005 \mathrm{mg} / \mathrm{L} \mathrm{TE}$ while the continuous treatment at 


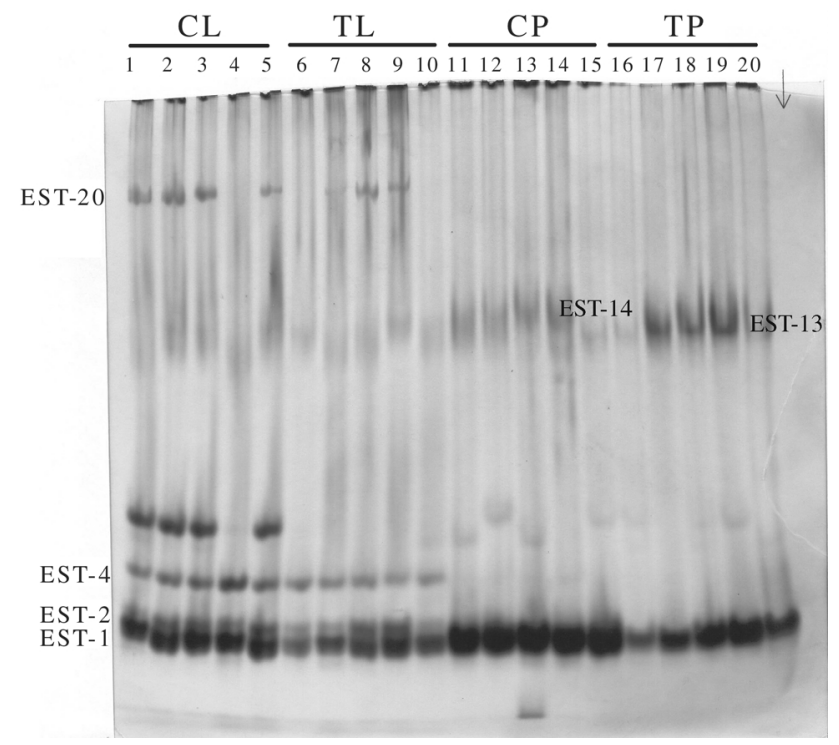

Figure 1 - A polyacrylamide gel showing esterase bands that presented changes in expression, in Aedes aegypti larvae and pupae submitted to continuous phenobarbital (PB) treatment and control. The results of five individuals per experiment are shown. $\mathrm{CL}=$ control larvae; $\mathrm{TL}=$ treated larvae; $\mathrm{CP}=$ control pupae; $\mathrm{TP}=$ treated pupae.

$0.02 \mathrm{mg} / \mathrm{L}$ TE was efficient for both SJ and GO larvae. This data indicates that the duration of the PB treatment and the population that is submitted to the treatment, with its genetic features and previous environmental experience, are also important in the results.

Comparisons between SJ and GO PB-pretreated mosquitoes regarding sensitivity to TE reinforced previous observations made on Drosophila melanogaster and Musca domestica (Yu and Terriere, 1973; Hällström et al., 1984; Lee and Scott, 1989; Scott and Lee, 1993; Fuchs et al., 1994) in which PB induced a higher level of tolerance in insecticide-susceptible strains than in insecticide-resistant ones. Without PB pretreatment, the OP-susceptible SJ larvae were more sensitive to the insecticide than the OP-resistant GO larvae. After discontinuous or continuous PB-pretreatment, larvae from both populations showed a significant decrease in mortality, but those from the SJ population responded with greater intensity to $\mathrm{PB}$ and was the only population that showed significantly decreased mortality at $0.005 \mathrm{mg} / \mathrm{L} \mathrm{TE}$ (Tables 1 and 2). Fuchs et al. (1994) explained the lower effect of $\mathrm{PB}$ on resistant $D$. melanogaster strains than on susceptible strains by suggesting that PB fails to induce the cytochrome isozymes (which are considered responsible for providing insecticide detoxification in this species) because the resistant strains have a higher basal level of such enzymes which enhances their capacity of degradation of PB.

Tolerance to PB has been mainly attributed to the induction of cytochrome P-450 and esterase isozymes (Carino et al., 1994; Fuchs et al., 1994; Kaliste-Korhonen et al., 1998). In order to look for mechanisms involved in the PB tolerance response of $A$. aegypti we tested these two possibilities by studying the effect of piperonyl butoxide (PBO) and the esterase patterns of PB-pretreated mosquitoes.

Treatment with $\mathrm{PBO}$ is a common procedure to detect cytochrome P-450 involvement in insecticide resistance because $\mathrm{PBO}$ inhibits mixed function oxidases and reduces the number of molecules available to interact with the insecticide and consequently reduces resistance. This effect was shown, for example, in Drosophila (Brun et al., 1996; Dombrowski et al., 1998) and Musca domestica (Liu and Scott, 1997).

In our study, when PB-non-pretreated larvae from São José do Rio Preto were pre-exposed to $\mathrm{PBO}$ and then to $\mathrm{TE}$, percentage mortality was higher in $\mathrm{PBO}$-treated larvae than in control, although the difference was not significant (Table 3). If we assume that there is some PBO activity, oxidases might partially explain the insecticide tolerance observed in PB-treated A. aegypti. In order to test this hypothesis, PB-pretreated SJ larvae were exposed to PBO, before or at the same time as TE. However, in both cases, significantly lower mortality rates (or higher levels of resistance) occurred, suggesting that oxidases are not involved at all. The reduction was considerably greater when PBO and TE were used simultaneously. One explanation might be that $\mathrm{PB}$ and $\mathrm{PBO}$ act in addition or synergistically, that is, $\mathrm{PBO}$ reinforces the effect of $\mathrm{PB}$. Thus, presumably, oxidases are not responsible for PB-induced tolerance in the strains studied. Support for this finding comes from data on organophosphate resistance studies using PBO in another mosquito, Culex pipiens, showing that oxidases are not involved (Wirth, 1998). Two highly active esterases or one insensitive acetylcholinesterase were the mechanisms considered responsible for tolerance in the two $C$. pipiens strains studied. It seems that the absence of involvement of oxidases in PB tolerance might be predominant in mosquitoes.

Relation between esterase activity and resistance to OP is well documented for a large number of insects. Resistant mosquitoes from many places in the world have been characterized over the last few years, revealing amplification of genes responsible for several closely related esterases. In Culex mosquitoes insecticide resistance is considered to be due to the amplification of detoxifying genes, resulting in the overproduction of carboxylesterases which detoxify the insecticides by sequestration, that is, by rapid binding and slow turnover (Fournier et al., 1987; Cuany et al., 1993; Jayawardena et al., 1994; Callaghan et al., 1998). In Culex pipiens, the increase of OP resistance was ascribed to a series of genetic events occurring over time: the overproduction of the esterase A1, which appeared in or about 1972, the selection of a mutated gene for insecticideinsensitive acetylcholinesterase around 1978, and the overproduction of esterases A4-B4 and A2-B2, detected around 1986 (Pasteur and Richmond, 1996). 


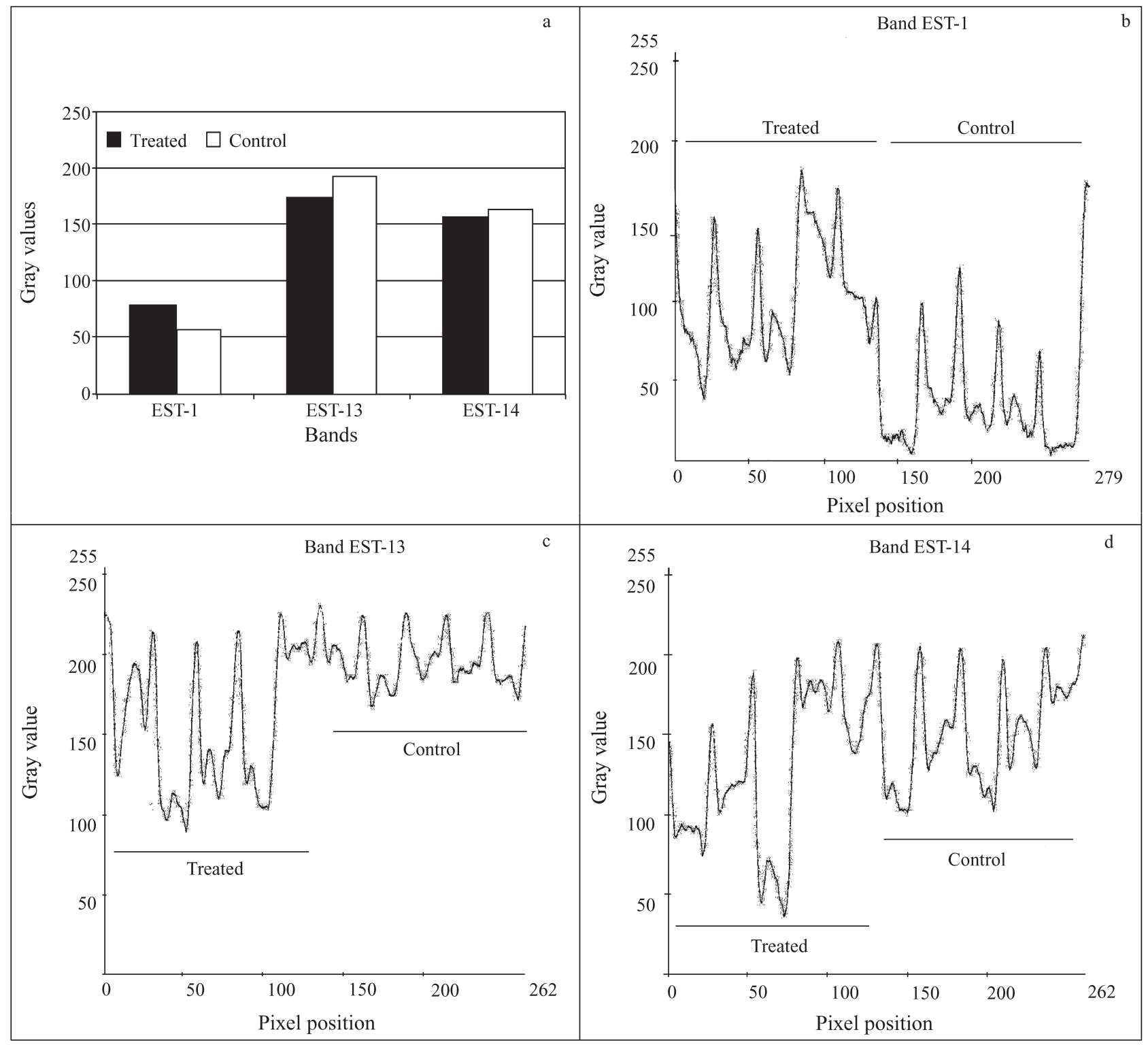

Figure 2(a-d) - (a) Distribution graph for staining degree mean values (in pixels) of esterase bands EST-1, EST-13 and EST-14, in continuous phenobarbital (PB) pretreated and control pupae from São José do Rio Preto. (b-d) Profile graphs of the same bands, obtained using the Global Lab Image Program.

Aedes aegypti mosquitoes from some regions also showed resistance to insecticides related with elevated esterase activity (Mourya et al., 1993; Mazzarri and Georghiou, 1995; Vaughan et al., 1998). In mosquitoes from São José do Rio Preto, which in the last 20 years have been submitted to control programs using different pyrethroid and organophosphorous insecticides, a carboxylesterase (EST-2) and a cholinesterase (EST-12) were considered as possibly involved in decrease of susceptibility (Lima-Catelani et al., 2004).

In our study, a significantly increased expression of esterase bands EST-13 and EST-14 was observed in continuously PB-treated larvae and pupae (Tables 4 and 5;
Figures 1 and 2). The frequency of PB-treated mosquitoes expressing the EST-14 band increased and also the number of those showing higher levels of activity was greater for esterase bands EST-13 and EST-14, being the difference in comparison with the control significant for EST-13.

The present results support the idea that PB-induced tolerance to TE in $A$. aegypti involves primarily the bands EST-13 and EST-14. Lima-Catelani et al., 2004 included these enzymes in the group of cholinesterases which have been considered to be involved in resistance to organophosphorous insecticides in some insects (Smissaert, 1964; Devonshire, 1975; Fournier and Mutero, 1994; Baxter and Barker, 1998; Zhu and Gao, 1999). Besides, the esterase 
band EST-12, which in the study of Lima-Catelani et al. (in press) showed changes of expression in mosquitoes from São José do Rio Preto when compared to mosquitoes from another population never exposed to insecticides, is also a cholinesterase that the same authors described as probably produced by an allele from the same locus which includes EST-13 and perhaps EST-14.

While the esterase bands EST-13 and EST-14 showed increased expression in PB-treated mosquitoes, bands EST-1, EST-2 and EST-20, which Lima-Catelani et al., 2004 classified as carboxylesterases, showed the opposite effect suggesting that, in this species, esterase gene inactivation is also part of the response to $\mathrm{PB}$.

Thus, resistance as well as tolerance-induction seem to be complex responses by the organisms involving the detoxifying genes, acting through mechanisms such as the selection of mutated genes, gene amplification and regulatory processes such as differential transcription activation or transcription enhancement of the detoxifying genes during development. Predominance of one or other of these processes is dependent on the inducing agent, the organism and its life history, as well as the environment. Knowledge of these mechanisms is important since they may eventually provide tools for interfering in the resistance process.

Previous studies on insecticide resistance of Brazilian A. aegypti populations carried out in our laboratory have indicated that mechanisms changing some esterase synthesis are involved in the process. In relation to the present study of PB-induced tolerance to TE in A. aegypti, esterase enzymes due to genes included in the same loci of the esterases found in those studies seem to be involved, supporting the idea of a common mechanism for insecticide resistance and induced tolerance by phenobarbital.

\section{Acknowledgments}

Thanks are due to FAPESP (Fundação de Amparo à Pesquisa do Estado de São Paulo) for a fellowship given to R.C. Sousa-Polezzi (n. 98/13708-0). The authors also thank Superintendência de Controle de Endemias (SUCEN) from São José do Rio Preto and Dr. Ionizete Garcia da Silva for supplying the mosquitoes and Dr. Peter James Harris for English language revision.

\section{References}

Ali B, Kaur S, James EC and Parmar SS (1985) Identification and characterization of hepatic carboxylesterases hydrolyzing hydrocortisone esters. Biochem Pharmacol 34:1881-1886.

Baxter GD and Barker SC (1998) Acetylcholinesterase cDNA of the cattle tick, Boophilus microplus: characterization and role in organophosphate resistance. Insect Biochem Molec Biol 28:581-589.

Brun A, Cuany A, Le Mouel T, Berge J and Amichot M (1996) Inductibility of the Drosophila melanogaster cytochrome P450 gene, CYP6A2, by phenobarbital in insecticide sus- ceptible or resistant strains. Insect Biochem Molec Biol 26:697-703.

Callaghan A, Guillemaud T, Makate N and Raymond M (1998) Polymorphisms and flutuactions in copy number of amplified esterase genes in Culex pipiens mosquitoes. Insect Mol Biol 7:295-300.

Carino FA, Koener JF, Plapp FW and Feyereisen R (1994) Constitutive overexpression of the cytochrome P450 gene CYP6A1 in a house fly strain with metabolic resistance to insecticides. Insect Biochem Molec Biol. 24:411-418.

Ceron CR, Santos JR and Bicudo HEMC (1992) The use of gelatin to dry celophane wound slab gels in an embroidering hoop. Rev Bras Genet 15:201-203.

Clement JG (1983) Effect of pretreatment with sodium phenobarbital on the toxicity of soman in mice. Biochem Pharmacol 32:1411-1415.

Cuany A, Handani J, Bergé J, Fournier D, Raymond M, Georghiou GP and Pasteur N (1993) Action of esterase B1 on chlorpyrifos in organophosphate-resistant Culex mosquitoes. Pestic Biochem Physiol 45:1-6.

Devonshire AL (1975) Studies of the acetylcholinesterase from houseflies (Musca domestica L.) resistant and susceptible to organophosphorous insecticides. Biochem J 149:463-469.

Dombrowski SM, Krishnan R, Witte M, Maitra S, Diesing C, Waters LC and Ganguly R (1998) Constitutive and barbitalinduced expression of the Cyp6a2 allele of a high producer strain of CYP6A2 in the genetic background of a low producer strain. Gene 221:69-77.

Dubois KP and Kinoshita F (1968) Influence of induction of hepatic microsomal enzymes by phenobarbital on toxicity of organic phosphate insecticides. Proc Soc Exp Biol 129:699-702.

Fournier D and Mutero A (1994) Modification of acetylcholinesterase as a mechanism of resistance to insecticide. Comp Biochem Physiol 108:19-31.

Fournier D, Bride JM, Mouchès C, Raymond M, Magnin M, Bergé JB, Pasteur N and Georghiou GP (1987) Biochemical characterization of the esterase $\mathrm{A} 1$ and $\mathrm{B} 1$ associated with organophosphate resistance in the Culex pipiens L. complex. Pestic Biochem Physiol 27:211-217.

Fuchs SY, Spiegelman VS and Belitsky GA (1994) Inducibility of various cytochrome P450 isozymes by phenobarbital and some other xenobiotics in Drosophila melanogaster. Biochem Pharmacol 47:1867-1873.

Hällström I, Blanck A and Atuma S (1984) Genetic-variation in cytochrome-p-450 and xenobiotic metabolism in Drosophila melanogaster. Biochem Pharmacol 33:13-20.

Jayawardena KGI, Karunaratne SHPP, Ketterman AJ and Heminguay J (1994) Determination of the role of elevated $B_{2}$ esterase in insecticide resistance in Culex quinquefasciatus (Diptera: Culicidae) from studies on the purified enzyme. Bul Entomol Res 84:39-44.

Johnson FM, Kanapi CG, Richardson RH, Wheeler MR and Stone WS (1966) An operational classification of Drosophila esterases for species comparison. Univ Texas Publ 6615:517532.

Kaliste-Korhonen E, Tuovinen K and Hänninen O (1998) Effect of phenobarbital and $\beta$-naphthoflavone on activities of different rat esterases after paraoxon exposure. Gen Pharmacol 31:307-312. 
Kaliste-Korhonen E, Törrönen R, Ylitalo P and Hänninen $\mathrm{O}$ (1990) Inhibition of cholinesterases by DFP and induction of organophosphate-detoxicating enzymes in rats. Gen Pharmacol 21:527-533.

Laemmli UK (1970) Cleavage of structural proteins during the assembly of the head of bacteriophage $\mathrm{T}_{4}$. Nature 227:680685 .

Lee SST and Scott JG (1989) Microsomal cytochrome P450 monooxygenases in the house fly (Musca domestica L.): biochemical changes associated with pyrethroid resistance and phenobarbital induction. Pestic Biochem Physiol 35:110 .

Lima-Catelani ARA, Bicudo HEMC and Ceron CR (2004) Genetic variation during development, revealed by esterase patterns of Aedes aegypti (Diptera: Culicidae). Biochem Gen 42:68-84.

Liu N and Scott JG (1997) Phenobarbital induction of CYP6D1 is due to a trans acting factor on autosome 2 in house flies, Musca domestica. Insect Mol Biol 6:77-81.

Macoris MLG, Camargo MF, Silva IG, Takaku L and Andrighetti MTM (1995) Modificação da susceptibilidade de Aedes (Stegomyia) aegypti ao temephos. Rev Patol Trop 24:31-40.

Macoris MLG, Andrighetti MTM, Takaku L, Glasser CM, Garbeloto VC and Cirino VCB (1999) Alteração de resposta de susceptibilidade de Aedes aegypti a inseticidas organofosforados em municípios do Estado de São Paulo, Brasil. Rev. Saúde Pública 33:521-522.

Mazzarri MB and Georghiou GP (1995) Characterization of resistance to organophosphate, carbamate, and pyrethroid insecticides in field populations of Aedes aegypti from Venezuela. J Am Mosq Control Assoc 11 (3):315-322.

Mood AM, Graybill FA and Boef DC (1974) Introduction to the Theory of Statistics. 3rd ed. Mc Grow-Hill, London.

Mourya DT, Hemingway J and Leake CJ (1993) Changes in enzyme titres with age in four geographical strains of Aedes aegypti and their association with insecticide resistance. Med Vet Entomol 7:11-16.

Pasteur N and Raymond M (1996) Insecticide resistance genes in mosquitoes: Their mutations, migration and selection in filed populations. J Heredity 87:444-449.

Plapp FW (1984) The genetic-basis of insecticide resistance in the housefly - Evidence that a single locus plays a major role in metabolic resistance to insecticides. Pest Biochem Physiol 22 (2):194-201.

Scott JG and Lee SS (1993) Tissue distribution of microssomal cytochrome P-450 monooxygenases and their inducibility by phenobarbital in the insecticide resistant LPR strain of house fly, Musca domestica L. Insect Biochem Mol Biol 23:729-738.

Smissaert HR (1964) Cholinesterase inhibition in spider mites susceptible and resistant to organophosphate. Science 143:129-131.

Steiner WWM and Johnson WE (1973) Techniques for electrophoresis of hawaiian Drosophila. US - IBP Island Ecosyst Tech Report 30:1-21.

Terriere LC (1984) Induction of detoxification enzymes in insects. Ann Rev Entomol 29:71-88.

Vaughan A, Chadee DD and Ffrench-Constant R (1998) Biochemical monitoring of organophosphorus and carbamate insecticide resistance in Aedes aegypti mosquitoes from Trinidad. Med Vet Entomol 12:318-321.

Wirth MC (1998) Isolation and characterization of two novel organophosphate resistance mechanisms in Culex pipiens from Cyprus. J Am Mosq Control Assoc 14:397-405.

Yu SJ and Terriere LC (1973) Phenobarbital induction of detoxifying enzymes in resistant and susceptible houseflies. Pest Biochem Physiol 3:141-148.

Zhu KY and Gao JR (1999) Increased activity associated with reduced sensitivity of acetylcholinesterase organophosphateresistant greenbug, Schizaphis graminum (Homoptera: Aphidae). Pestic Sci 55:11-17.

EditorAssociado: Carlos F.M. Menck 